\title{
Innate and adaptive autoimmunity in type 1 diabetes
}

Morran MP, McInerney MF, Pietropaolo M. Innate and adaptive autoimmunity in type 1 diabetes. Pediatric Diabetes 2008: 9: 152-161.

\section{Michael P Morrana, Marcia F Mclnerney ${ }^{b}$ and Massimo Pietropaolo ${ }^{a}$}

aLaboratory of Immunogenetics, The Brehm Center for Type 1 Diabetes Research and Analysis, Division of Metabolism, Endocrinology \& Diabetes, Department of Internal Medicine, University of Michigan Medical School, Ann Arbor, MI, USA; and ${ }^{b}$ Department of Medicinal and Biological Chemistry, College of Pharmacy, University of Toledo, Toledo, OH, USA

Key words: autoimmunity - innate immunity - T1D - TLRs

Corresponding author: Massimo Pietropaolo, MD

Laboratory of Immunogenetics

The Brehm Center for Type 1 Diabetes

Research and Analysis

2039, Biomedical Scientific Research

Building

109 Zina Pitcher Place

Ann Arbor

MI 48109

USA.

Tel: (734) 615-2574;

fax: (734) 936-6684;

e-mail: maxtp@umich.edu

Submitted 22 May 2007. Accepted for publication 21 August 2007

\section{Overview of the immune system}

The immune system is a complex network of cells and organs that has developed to protect the body against pathogens. This complex system employs multiple specialized cell types working and communicating together through cytokines and cellular interactions. The immune system is a powerful system that requires delicate regulation in order to prevent autoimmune complications from occurring. Proper regulation and control of immune responses are necessary in differentiating against foreign pathogens and the self.
The immune system is composed of two branches, the innate immune system and the adaptive immune system. The innate immune system works as the first line of defense against pathogens, working to recognize common recognition components of pathogens so that further immune responses can be signaled in the presence of foreign pathogens. The adaptive immune system is an antigen-specific system that generates immunological memory and antibody responses, specific to pathogens or infected cells. The innate and adaptive immune systems work as one unified system with the goal to protect the body. 
Although the immune system has evolved to protect the host, it also possesses the power to damage the host. Overactive immune responses that fail to differentiate between the self and the non-self can give rise to autoimmune disorders. This article seeks to provide current information on components of both the innate and adaptive immune systems and illustrate how they effect the development and pathogenesis of autoimmune disease, specifically that of type 1 diabetes (T1D). Understanding how the immune system is failing to regulate and control immune responses are vital in understanding how to control these autoimmune disorders.

\section{Autoimmunity in T1D}

T1D is an autoimmune disease in which pathogenic $T$ cells specifically target the destruction of insulinproducing cells within the pancreas. Without the hormone insulin, the body is unable to maintain normal blood glucose levels. Therefore, individuals suffering from T1D must inject insulin multiple times daily to survive.

Genome-wide association studies in T1D have identified over 20 putative loci of statistical significance, but thus far, only linkage to human leukocyte antigen (HLA) seems incontestable (1). The search for non-HLA susceptibility genes has received great attention in recent years, and a region on chromosome 16p13, identified as KIAA0350, appears to be as a novel locus associated with T1D (2).

T1D is a complex polygenic disease (3) for which there is a small number of genes with large effects (i.e., HLA) and a large number of genes with small effects (1). Risk of T1D progression is conferred by specific HLA DR/DQ alleles [e.g., DRB1*03-DQB1*0201 (DR3) or DRB1*04-DQB1*0302 (DR4)] $(4,5)$. The genotype associated with the highest risk for T1D is the DR3/4-DQ8 (DQ8 is DQA1*0301, DQB1*0302) heterozygous genotype. In addition, HLA genotypes such as DQB1*0602 confer dominant protection from T1D in multiple populations. There is a different disease risk for each major histocompatibility complex (MHC) genotype, and although it is possible that only a single peptide epitope will relate to disease with multiple MHC genotypes, this controversy remains to be evaluated experimentally.

A recent report provided evidence that risk for islet autoimmunity dramatically increased in DR3/4-DQ8 siblings who shared both HLA haplotypes with their diabetic proband sibling ( $63 \%$ by age 7 and $85 \%$ by age 15) as compared with siblings who did not share both HLA haplotypes with their diabetic proband sibling (6). These data suggest that HLA genotyping at birth may identify individuals at high risk of developing T1D before the occurrence of clear signs of islet autoimmunity.
The onset of T1D has been well characterized and occurs in a two-step manner of first asymptomatic inflammation of the pancreatic islets and second by a distinctive autoimmune process that leads to a decline in the pancreatic $\beta$-cell function and mass. Cells from both the innate and adaptive immune systems can be found within an insulitis lesion including $\mathrm{T}$ lymphocytes, $\mathrm{B}$ lymphocytes, macrophages $(\mathrm{M} \Phi)$, and natural killer (NK) cells (7-11). The autoimmune destruction of the pancreatic $\beta$ cells takes place in a cell-mediated, organ-specific manner and requires both CD4+ and CD8 + T cells $(8,12,13)$ as well as $\mathrm{M} \Phi$, which might be the first immune system cells present in the islets (12-17).

Activated $M \Phi$ present in the islets are able to secrete nitrogen and oxygen free radicals as well as various proinflammatory cytokines into their environment including: interleukin-1 $\beta$ (IL-1 $\beta$ ), interleukin-12 (IL-12), interleukin-8, and tumor necrosis factor $\alpha$ (TNF $\alpha)$ (18). Nitrogen and oxygen free radicals can directly penetrate cells causing intracellular damage to DNA, lipids, and proteins. The cytokines secreted from the activated $\mathrm{M} \Phi$ can also invoke a response that initiates cellular damage in addition to free radical damage. Research has indicated that TNF $\alpha$ and IL-1 $\beta$, produced by $\mathrm{M} \Phi$, along with interferon (IFN) $\gamma$, produced by neighboring $\mathrm{T}$ cells, have a toxic effect on $\beta$ cells (19). It has also been demonstrated that a lack of IL-12, because of $M \Phi$ depletion experiments, actually prevents the differentiation of $\beta$-cell cytotoxic $\mathrm{T}$ cells in non-obese diabetic (NOD) mice (20-22). Returning $\mathrm{M} \Phi$ into the above-mentioned $\mathrm{M} \Phi$-depleted environment returns the ability of the immune system to generate active $\beta$-cell cytotoxic T cells in the NOD mouse (20-22). These results indicate that cytokines not only can directly damage $\beta$ cells but also can lead to indirect $\beta$-cell damage by activating other cell types.

Once the innate immune system has been activated within the pancreas, an adaptive immune response is subsequently triggered, generating autoreactive $\mathrm{T}$ cells, B cells, and antibodies. As T1D progresses in severity, so does the number of autoantigens targeted by $\mathrm{T}$ cells and autoantibodies being produced by B cells (23). As pancreatic material is destroyed, $\mathrm{T}$ cells can be triggered to become autoreactive, wherein they present increased amounts of self-antigens from the damaged tissue. $\mathrm{T}$ cells that become autoreactive can activate $\mathrm{B}$ cells and signal generation of autoantibodies. This phenomena, known as epitope spreading, is illustrated once autoreactive $\mathrm{T}$ cells and $\mathrm{B}$ cells are fully capable of generating autoantibodies directed against numerous islet self-antigens including insulin, glutamic acid decarboxylase, $65-\mathrm{kDa}$ isoform, islet cell antibody (ICA512)/islet antigen-2 (IA-2), and IA-2 $\beta$ (23). Researchers are currently focusing on the study of the innate immune system to understand and determine its role in autoimmune disorders, such as T1D. 


\section{Adaptive immune system}

The immune system is comprised of two branches: the adaptive immune system and the innate immune system. The adaptive immune system functions to establish immunological memory and adapts to eliminate reoccurring pathogens more effectively and efficiently upon repeat exposure from a given pathogen. The adaptive immune system is an antigen-specific system that detects non-self molecules through the recognition of peptide antigens utilizing receptor interactions between $T$ cells and antigen-presenting cells (APCs). Adaptive immunity establishes long-term immunological memory responses that trigger clonal expansion of $\mathrm{T}$ lymphocytes, which in turn work to signal $\mathrm{B}$ cells to produce antigen-specific antibodies (24). T lymphocytes are somatically generated within the thymus, each with a structurally diverse and unique T cell receptor (TCR). The TCR functions to recognize processed peptides presented in the context of MHCs. Peptides presented through MHC Class-I structures interact with $\mathrm{CD} 8+\mathrm{T}$ cells, while those peptides presented through MHC Class-II structures interact with $\mathrm{CD} 4+\mathrm{T}$ cells. Once a processed peptide is recognized through a MHC-TCR interaction, a cascade of signaling events occurs, dependent upon the class of MHC structure recognized and the $\mathrm{T}$ cell type that is activated. Once activated, CD4 $+\mathrm{T}$ cells promote $\mathrm{T}$ cell activation and differentiation, along with the ability to signal B cells to generate an antibody response. $\mathrm{CD} 8+\mathrm{T}$ cells when activated produce inflammatory mediators and can directly target the destruction of specific peptide-presenting cells.

The adaptive immune system has been well studied in the context of T1D development in both humans and the NOD mouse model system. Both T and B lymphocytes accumulate within the islet lesions, where they are triggered to initiate a full-blown immune response toward self-antigens. $\mathrm{M} \Phi$ and monocytes first cause inflammation in the islets, followed by $\mathrm{T}$ and $\mathrm{B}$ cell infiltration. At this point, an individual still has the capability to synthesize insulin at a normal level. In an islet lesion, APCs present self-peptides to $\mathrm{T}$ cells. Once activated against self-peptides, $\mathrm{T}$ cells can go on to promote an autoimmune response and signal B cells to produce antibodies against selfantigens. During the development of diabetes, MHC Class-I restricted $\mathrm{T}$ cells are critical for disease pathogenesis in both humans and the NOD mouse $(25,26)$. Autoreactive CD $8+\mathrm{T}$ cells appear to target self-antigens including insulin (27) and the isletspecific glucose 6-phosphatase catalytic subunitrelated protein (28). Once cell types of the adaptive immune system become fully activated against selfantigens, the destruction of the $\beta$ cells ultimately occurs. Although this process is well understood, attempts to control and prevent this destructive signal from occurring have failed to yield efficacious protection from disease onset.

\section{Regulatory T cells}

Regulatory $\mathrm{T}$ cells ( $\mathrm{T}$ regs) are a specific population of $\mathrm{T}$ cells that are CD4+ CD25+ that generally express the forkhead transcription factor, forkhead box P3 (29-31). T regs have been characterized because of their ability to suppress proliferation of effector $\mathrm{T}$ cells by shutting down interleukin-2 (IL-2) (32). Researchers have currently been focusing on the use of $\mathrm{T}$ regs in the prevention of T1D and other autoimmune diseases. Autoimmunity can develop because of a lack of $\mathrm{T}$ cell homeostasis, resulting from an inability to control or prevent chronic $\mathrm{T}$ cell activation from occurring. $\mathrm{T}$ regs possess the ability to control and prevent $\mathrm{T}$ cell activation and the signaling of chronic inflammatory responses $(33,34)$. Unregulated effector $\mathrm{T}$ cells can become overactive and run the risk of becoming autoreactive if $\mathrm{T}$ regs are not able to regulate a proper immune response from occurring. Therefore, utilizing $\mathrm{T}$ regs to modulate effector $\mathrm{T}$ cells responses in an effort to prevent autoimmunity has become a strong area of research.

$\mathrm{T}$ regs are thought to control every aspect of autoimmune pathogenesis from expansion of $\mathrm{T}$ cell populations and $\mathrm{T}$ cell differentiation for influencing effector $\mathrm{T}$ cell function (35). Although individuals with T1D have relatively equal numbers of $\mathrm{T}$ regs present compared with healthy controls (36-38), $\mathrm{T}$ regs isolated from patients with T1D displayed decreased suppressive activity in vitro, which suggests a defect in T reg function in individuals with T1D (36, 37). Adoptive transfer experiments utilizing $T$ regs in NOD mice show that $\mathrm{T}$ regs have the capability to cause distinct protective effects on T1D disease incidence and progression (39). Adoptive transfer of $\mathrm{T}$ regs can be carried out with either a polyclonal $\mathrm{T}$ reg population or a more antigen-specific population of $\mathrm{T}$ regs. Experiments utilizing adoptive transfer of $\mathrm{T}$ regs into NOD mice illustrate that an islet antigen-specific population of $\mathrm{T}$ regs are 50 times more effective at preventing diabetes than a polyclonal population of $\mathrm{T}$ regs (35). Researchers observed that effective prevention of diabetes onset is directly correlated with the ability of the $\mathrm{T}$ regs to become activated in the pancreatic lymph node (40). $\mathrm{T}$ regs possess the ability to control immune responses in both the lympoid organs and the periphery at the site of an inflammatory response (35). The possibility to utilize $\mathrm{T}$ regs therapeutically to prevent T1D in humans still needs more focused research, although preemptive trials utilizing adoptive transfer of $\mathrm{T}$ regs in graft-vs.-host disease therapy are currently taking place (35). 


\section{Natural killer $\mathrm{T}$ cells}

Natural killer T (NKT) cells are another subtype of $\mathrm{T}$ cells that has been identified as an important regulator of autoimmunity and T1D. NKT cells are a unique cell type that share common characteristics with both NK cells and T cells. NKT cells are capable of causing direct cell lysis because of Fas-ligand interactions along with the ability to induce cytotoxic effects on cells because of the production of IFN $\gamma$ (41-43). A subset of NKT cells, which are biased toward TCR usage, recognize glycolipid antigens and express high levels of interleukin 4 (IL-4) (41-43). Upon activation through $\alpha$-galactosylceramide, a specific glycolipid ligand, these TCR-biased NKT cells produce type 2 helper $\mathrm{T}$ cell response (Th2-type) responses mediated through IL-4 and interleukin-10, which inhibit type 1 helper $\mathrm{T}$ cell response (Th1) responses $(44,45)$. NKT cells are numerically and functionally deficient in the thymus of diabetes-prone NOD mice $(46,47)$. Humans suffering from T1D display a reduction in the frequency of total NKT cells along with a diminished capacity of NKT cells to secrete IL-4 (48). Adoptive transfer experiments utilizing NKT cells afford protection against the development of diabetes in NOD mice (49). Thymus-derived NKT cells afford greater protection against T1D development than splenicderived NKT cells in NOD mice (50). Continued research is necessary to fully determine how to utilize this unique subset of NKT cells to afford disease protection against T1D and autoimmunity in humans.

\section{Innate immune system}

The innate immune system functions as the first line of defense against microbes and infection. Unlike the adaptive immune system, the innate immune system does not generate long-term immunological memory. The innate immune system, once thought to be very non-specific, illustrates a much greater degree of specificity than previously thought (12). This system employs multiple cell types including $M \Phi$, dendritic cells (DCs), NK cells, neutrophils, and epithelial cells, each of which has its own specific function in an innate response from phagocytosis of infectious pathogens to direct targeted lysis of infected host cells.

In order to initiate an innate immune response, the host system first interacts with common surface molecules, expressed by an infectious organism. These common microbial surface molecules originally termed pathogen-associated molecular patterns (PAMPs) were predicted to interact with pattern recognition receptors (PRRs) found on the surface of cells. In contrast to adaptive immune system receptors, PRRs are not clonal receptors and lack the ability for clonal expansion (5153). The once hypothesized PRRs are now known to exist. One of the most commonly recognized groups of PRRs is the Toll-like receptors (TLRs) $(51,53,54)$.

\section{TLRs}

TLRs are an evolutionarily conserved class of receptors, consisting of 13 identified members in mammals $(51,53,54)$. TLRs share common structural features of a type I integral membrane glycoprotein, consisting of leucine-rich repeats in an extracellular domain and having a Toll/interleukin-1 receptor (IL-1R) (TIR) cytoplasmic domain $(51,53)$. TLRs are PRRs and, as hypothesized, recognize many PAMPs including microbial membrane-derived molecules through TLR-2 and TLR-4, bacterial flagellin through TLR-5, as well as DNA and RNA from bacteria and viruses through TLRs 3, 7, 8, and $9(51,53,54)$. Although the majority of TLRs (TLRs 1, 2, 4, 5, and 6) are found externally on the cell surface, some (TLRs 3 , 7,8 , and 9) are found within the intracellular compartments (54). TLRs also possess the ability to recognize a number of self-molecules expressed by the mammalian host (55), particularly molecules that are indicators of stress and disease (56) or molecules that are modified by a disease process. Oxidation (57) and the breakdown of extracellular matrix components (58) at the site of stress and inflammation are processes that convert self-molecules into ligands of TLRs.

Ligand binding to a specific TLR initiates a cascade of cell signaling and cellular activation. TLR signaling utilizes similar molecules to those used through IL-1R signaling (54). Although each TLR has its own unique set of ligands, most TLRs utilize the adaptor protein myeloid differentiation factor 88 (MyD88) to internalize cell signaling; however, multiple internal activation pathways exist for TLRs (54). TLR-activated cells respond by upregulating the production of numerous proinflammatory cytokines, chemokines, and costimulatory molecules to heighten innate immune cell sensitivity and to promote activation of the adaptive immune system $(50,51,59-61)$.

A general model of TLR signaling and activation is presented in Fig. 1. TLRs (TLRs 1, 2, 4, 5, 6, 7, 8, 9, and 11) can promote cell activation through the MyD88-dependent pathway, but some of these TLRs can also carry out TLR activation in a MyD88independent manner as well. TLRs and MyD88 association elicits the interleukin-1 receptor-associated kinase (IRAK) family. The IRAKs serve to activate tumor necrosis factor receptor-associated factor 6 , which then signals activation of the transforming growth factor- $\beta$-protein kinase 1 (TAK1) complex. TAK1 ineracts with TAK1-binding proteins (TABs) to form the TAK1/TABs complex and when activated signals both the nuclear factor- $\kappa \mathrm{B}(\mathrm{NF}-\kappa \mathrm{B})$ essential modulator (NEMO)/inhibitory kappa kinases (IKKs) complex and the mitogen-activated protein kinases 


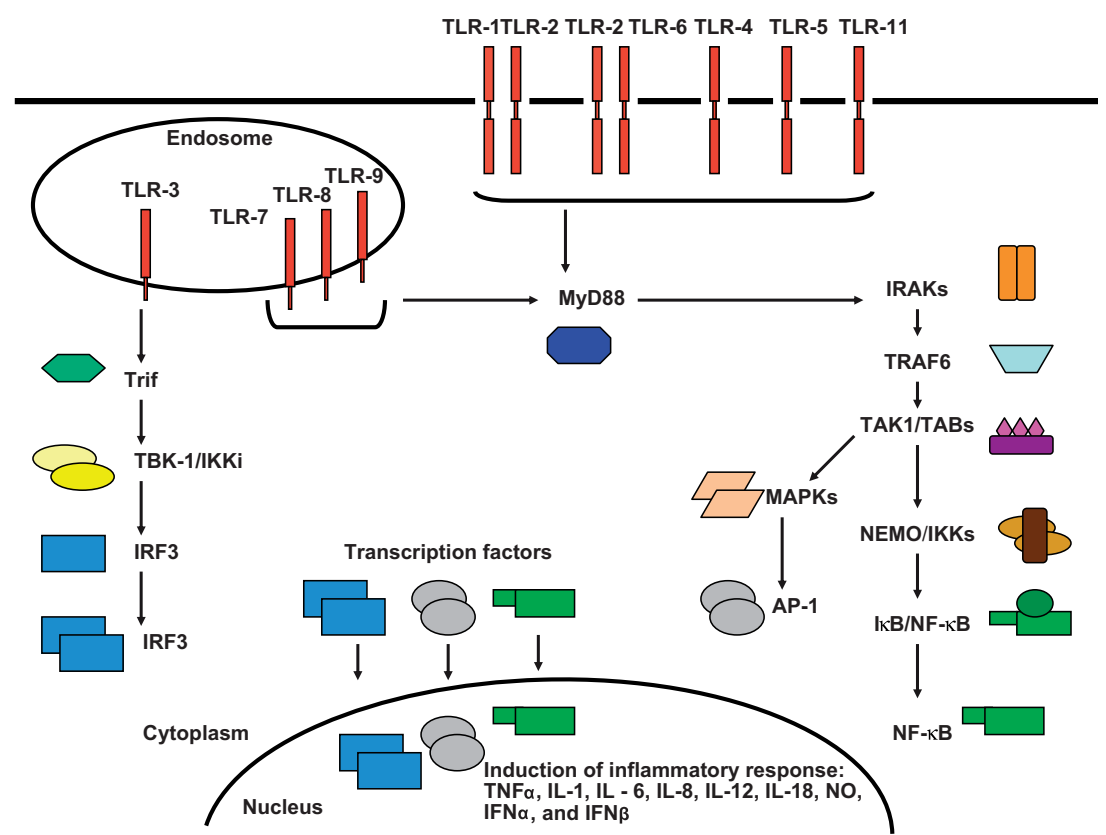

Fig. 1. Toll-like receptor (TLR)-mediated cell activation and signaling, general model. TLRs (TLRs 1, 2, 4, 5, 6, 7, 8, 9, and 11) promote cell activation through the myeloid differentiation factor 88 (MyD88)-dependent pathway. MyD88 signals interleukin-1 receptor-associated kinase (IRAK), which lead to tumor necrosis factor receptor-associated factor 6 (TRAF6) recruitment. TRAF6 mediates activation of the transforming growth factor- $\beta$-protein kinase 1/TAK1-binding proteins (TAK1/TABs) complex. The TAK1 complex signals both the nuclear factor $-\kappa B(N F-\kappa B)$ essential modulator (NEMO)/IKK complex, which results in I $\kappa$ B catalysis, leading to the activation of the NF- $\kappa$ B and the mitogen-activated protein kinases (MAPKs), which phosphorylate activating protein-1 (AP-1), leading to AP-1 activation. TLR-3 signaling utilizes the Toll/interleukin-1 receptor domain-containing adapter-inducing IFN $\beta$ (Trif)-dependent pathway. Trif activation mediates signaling through the tank-binding kinase-1 (TBK-1)/IKKi complex. TBK/IKKi complex mediates the phosphorylation of interferon regulatory factor3 (IRF3). Phosphorylated IRF3 dimerizes and is free to translocate into the nucleus. Free activated IRF3, AP-1, and NF-кB can translocate into the nucleus, where they influences expression of various inflammatory cytokines and costimulatory molecules. IFN, interferon; IL, interleukin; $\mathrm{NO}$, nitric oxide; $\mathrm{TNF} \alpha$, tumor necrosis factor $\alpha$.

(MAPKs). Activation of the NEMO/IKKs complex results in inhibitory kappa B kinase (IкB) catalysis, which leads to activation of free NF- $\mathrm{KB}$. Activation of the MAPKs leads to the phosphorylation of activating protein-1 (AP-1).

TLR-3 activation occurs through the TIR domaincontaining adapter-inducing IFN $\beta$ (Trif) pathway. Activated Trif signals through the tank-binding kinase-1 (TBK-1)/inducible IкB kinase (IKKi) complex. The TBK-1/IKKi complex mediates the phosphorylation of interferon regulatory factor-3 (IRF3), which then dimerizes. Free activated IRF3, AP-1, and NF- $\mathrm{KB}$ can translocate into the nucleus from the cytoplasm where they influence gene expression of various inflammatory cytokines and costimulatory molecules (61). Figure 1 represents only a general view of TLR signaling pathways (61).

Recent data implicate signal transduction through TLRs in the development of T1D in the NOD mouse. Knocking out expression of MyD88, the adapter protein responsible for most TLR signal transduction, protects NOD mice against the development of diabetes (62). Loss of TLR-4 expression in the NOD mouse, however, leads to a higher incidence of diabetes compared with that of non-deficient TLR-4 littermates, whereas loss of TLRs 2, 3, or 9 has no effect on the development of diabetes (62). Signaling through MyD88 appears to be important in T1D development, but the exact mechanistic details and specific TLR involvement remain to be elucidated.

Activation of the innate immune system acts as a prerequisite for the induction of an acquired immune response, particularly those of a $\mathrm{T}$ helper 1 cell response $(52,57,58)$. It has been suggested that TLRs are responsible for priming the adaptive immune system to become autoreactive toward self-antigens, thus ultimately controlling the progression of autoimmunity in diseases such as T1D, systemic lupus erythematosus (SLE), rheumatoid arthritis, Crohn's disease (63), and heart failure (64). TLRs triggered through self-ligands could promote an unwarranted immune response, which in turn could non-specifically activate $T$ cells because of cytokine and inflammatory signals.

\section{Non-TLR PRRs}

TLRs are one part of the innate immune system that has been extensively researched since their initial discovery in Drosophila in the late 1990s (51, 53). Numerous non-TLR-associated innate immune receptors have recently been receiving attention including nod-like 
receptors (NLRs) (65), triggering receptors expressed on myeloid cells (TREMs) (66), and C-type lectin receptors (CLRs) (67); although these receptors have not been directly linked to T1D or autoimmunity, they represent a novel area for future exploration. TLRs are localized either at the cell surface or intracellular within compartments, such as endosomes (54). NLRs are the cytoplasmic equivalent of TLRs (65). NLRs are a family of PRRs capable of detecting pathogens within the cell cytosol $(54,65)$. NLRs, although poorly understood, have been illustrated to induce inflammatory responses upon activation within the cytosol (65). NLRs and TLRs work together to survey the entire cell against pathogens, but the exact details and specific signaling pathways are still unknown. TREMs function mainly as immune modulators, participating in numerous cell processes from regulating differentiation and function of $\mathrm{M} \Phi$ and DCs for actively amplifying the effects of inflammation (66). Defective TREMs have the potential to promote activation or amplify inflammation, leading to unnecessary innate and adaptive immune system activation. CLRs mediate host defense by binding PAMPs and function to activate and inhibit innate immune responses to pathogens or self (67). Malfunctions in CLRs may promote inflammation because of a possible inability to properly signal the end of an innate immune response. The distinct relationship between non-TLR and TLR PRRs is not well understood, but the possibility of synergy or cross talk between these unique innate systems definitely possesses the potential to perpetuate and induce an adaptive immune response. Malfunctions in any of these innate systems or receptors, especially those responsible for amplifying or regulating an inflammatory response, could potentially trigger adverse and possibly detrimental immune responses, which may lead to a break in tolerance.

\section{Innate influences over adaptive immunity}

Although the innate and adaptive immune systems are discussed as two separate entities, both systems interact and communicate with one another. Each system has its own unique responsibilities that are beneficial for the health of the individual. The two immune systems communicate through physical cell surface recognition molecules and chemically through the release or uptake of various cytokines. Autoimmunity, uncontrolled inflammation, and chronic immune responses turn the most influential defense mechanism of the body into a ticking time bomb with the potential to cause serious damage.

TLRs can recognize and bind both non-self and selfantigens $(51,53,56,58)$. It has been proposed that PRRs that can interact with self-antigens have the ability to break central tolerance and signal an adap- tive immune response, leading to the development of autoimmunity (64). Ligand binding to a specific TLR initiates a specific cytokine production pattern. In general, TLR activation leads to the production of proinflammatory cytokines and mediators. In an unbalanced or compromised immune setting, an overt proinflammatory response may result in autoimmune diseases (68).

Specific studies on Crohn's disease suggest that innate immune responses to bacterial flagella through TLR5-flagellin binding may actually promote an adjuvant-like effect on the adaptive immune system, thus prompting uncontrolled inflammatory responses in the adaptive immune system that promotes autoimmunity (63). In SLE, TLR interactions with selfDNA, self-RNA, or self-nucleotide complexes through interactions with TLRs $3,7,8$, and 9, all of which bind nucleotide molecules, have been proposed as an initiating trigger for the development of autoimmunity, termed the toll hypothesis (64). Although the main function of PRRs is to bind bacterial and viral components, binding of self-nucleotide particles may lead to the stimulation of an innate immune response that elicits an autoimmune adaptive response, thus perpetuating the potential for the development of autoimmunity.

It is known that $\mathrm{M} \Phi$ are the first cell type present within an islet lesion and are required for T1D disease progression (12-17). М $\Phi$ function mainly as phagocytic cells but also act as APCs, and once activated, produce multiple inflammatory cytokines and free radicals, capable of damaging $\beta$ cells (13). МФ infiltrate first into a lesion, and then, an adaptive autoimmune response is triggered activating CD4+ and CD8 $+\mathrm{T}$ cells to become autoreactive $(8,12,13)$. MФ have been thought to be the initiating cell type of T1D disease progression because of the protective nature on disease onset in $\mathrm{M} \Phi$ depletion experiments and their ability to produce cytokines, which are responsible for the activation of both innate and adaptive immune responses (20-22). Once activated, МФ in an inflammatory lesion could easily target and present self-peptides to the incoming $\mathrm{T}$ cells. Once these $\mathrm{T}$ cells become autoreactive or effector in function, downregulating the immune response becomes difficult because of a lack of $\mathrm{T}$ reg function, previously mentioned in individuals predisposed and those suffering from T1D.

Several viruses have also been implicated as potential triggers of T1D including adenovirus, Coxsackie B virus, cytomegalovirus, hepatitis $\mathrm{C}$ virus, mumps virus, and rubella virus (69-72). As TLR-3 is known to recognize viral intermediate double-stranded RNA (dsRNA) and its mimic poly(I)poly(C) $(51,53,54)$, it has been receiving much attention as a possible link in the development of T1D and autoimmunity. TLR-3 activation leads to the production of IFNs, which 
serve to stimulate APCs and the adaptive immune system (61). It has been demonstrated that bone marrow-derived $M \Phi$ from diabetic NOD mice express significantly higher basal levels of TLR-3 than that of prediabetic NOD mice and control strains (73). Furthermore, stimulating these $\mathrm{M} \Phi$ with poly(I)poly(C) elicits a nine-fold increase in production of type 1 IFNs in diabetic animals compared with non-diabetic controls (73). It is not yet known what exact contribution this elevated TLR-3 expression has on T1D disease progression or onset, although one group has illustrated that TLR-3 expression in islets may be partially responsible for diabetes development in rat insulin promoter-B7.1 mice on a $\mathrm{BALB} / \mathrm{c}$ genetic background when diabetes is precipitated with poly(I) poly $(\mathrm{C})$ and insulin B9-23 peptide (74).

A recent report indicated that loss of TLR-3 expression has no effect on the development of diabetes in the NOD mouse (62). However, following viral infection, dsRNA intermediates or double-stranded DNA in the cytosol can trigger signal transduction leading to the production of type 1 IFNs by binding intracellular PRRs, retinoic-acid-inducible gene-1 (RIG-1), or melanoma-differentiation-associated gene5 (MDA-5), thus bypassing TLR-3 (75). Involvement of RIG-1 and MDA-5 in the context of diabetes development has not been assessed.

TLR activation could lead to chronic inflammatory responses, which may potentially steer the immune system down a path toward autoimmunity instead of host defense. Humans recently diagnosed with T1D display significantly higher levels of $\mathrm{TNF} \alpha$, IL-2, and other proinflammatory cytokines in their peripheral blood (76). It has also been shown that the presence of high blood glucose concentrations has the ability to induce the expression of proinflammatory molecules in monocytes (77). In a system where it is key to control $\mathrm{T}$ cell activation, excessive IL-2 along with the induction and production of proinflammatory cytokines makes $\mathrm{T}$ cell homeostatic control even more difficult for patients with T1D.

Studies utilizing NOD mice have revealed that newonset diabetic NOD mice have the potential to generate bone marrow-derived $M \Phi$, which exhibit altered basal expression patterns of TLRs, that is, Th1 biased and upon activation produces heightened cytokine production compared with normal mice (73). These bone marrow-derived M $\Phi$ have increased TLR expression, TLR signaling responses, and heightened cytokine expression and production (73). Although these $\mathrm{M} \Phi$ are generated in vitro, it is likely that the precursor cells in vivo may give rise to tissue $M \Phi$ with similar altered characteristics. Hypersensitive proinflammatory $М \Phi$ may promote a chronic inflammatory state, which could induce uncontrolled $\mathrm{T}$ cell activation and shift the immune system toward autoimmune responses.
Even though TLRs are thought of as being solely involved in the innate immune system, research has indicated that TLRs are expressed in cells of the adaptive immune system as well (78). TLRs are expressed by $\mathrm{T}$ cells and possess the ability to modify $\mathrm{T}$ cell activities (78). $\mathrm{T}$ cells from human peripheral blood samples show expression of TLRs 1, 2, 3, 4, 5, 7, and 9, although individual expression levels for each TLR vary (79-81). TLR expression is regulated through concomitant TCR-dependent stimulation, but costimulation of TLRs and the TCR can influence $\mathrm{T}$ cell function and proliferation (78). Although this topic is relatively new, certain TLRs (TLRs 2, 3, 5, and 9) have been categorized as being able to modify and enhance $\mathrm{T}$ cell proliferation and cytokine production of TCR-stimulated T cells (78). Additional studies on $\mathrm{T}$ regs have illustrated that activation of TLRs 2, 5, and/or 8 has the ability to suppress $\mathrm{T}$ reg activity (78).

One could hypothesize a bacterial infection that elicits TLR-2 and TLR-4 activation. TLR activation may lead to the enhancement of effecter $T$ cells not only from cytokine signals produced through cells of the innate immune system but also from direct TLR2 recognition by $\mathrm{T}$ cells themselves. Diabetic individuals or those progressing toward T1D may have T regs that lack proper homeostatic function. Add to this bone marrow precursor cells that when differentiated generate proinflammatory cell types and you have an immune system that is primed to generate inflammatory responses with an inability to stop or regulate them. This type of system could easily steer unregulated, chronically activated cell types toward autoimmunity. More in-depth research into this topic needs to be generated, but one could envision how an inflammatory biased system could be triggered upon a simple bacterial infection.

\section{Conclusion}

The immune system as a whole has developed to prevent damage and sustain the health of the host. The once overshadowed innate immune system has a vital role in host defense and the signaling of an adaptive immune response. Malfunctions in either immune system have the potential to lead to autoimmune complications, but recently, the roles of the innate immune system in perpetuating autoimmunity has become an interesting area of research focus, especially in T1D. The innate system primes the entire immune system to signal a full-blown adaptive immune response in the face of an infection. T1D is an autoimmune disease that requires cell types from both the innate and adaptive immune system for disease progression. Although the exact trigger to initiate the adaptive immune response responsible for signaling the destruction of the $\beta$ cells in the pancreas is not 
fully understood, looking toward malfunctions and or signaling through the innate system is necessary to fully understand the development of autoimmunity in T1D. Effectively manipulating TLR signaling may help to elucidate the underlying mechanisms of T1D development. Discovering novel potential candidate receptors or molecules capable of affording protection against T1D is necessary in order to design therapeutic strategies in an effort to find a cure for T1D.

\section{Acknowledgements}

This work was supported by the National Institutes of Health grants R01 DK53456 and R01 DK56200 (M. P.), R21DE014486 (M. F. M), and United States Department of Agriculture/ Cooperative State Research, Education and Extension Service OHOW-2005-06321 (M. F. M).

\section{References}

1. Todd JA, Walker NM, Cooper JD et al. Robust associations of four new chromosome regions from genome-wide analyses of type 1 diabetes. Nat Genet 2007: 39: 857-864.

2. Hakonarson H, Grant SFA, Bradfield JP et al. A genome-wide association study identifies KIAA0350 as a type 1 diabetes gene. Nature 2007 (Epub) doi: 10.1038/ nature 06010 .

3. Thomson G. HLA DR antigens and susceptibility to insulin-dependent diabetes mellitus. Am J Hum Genet 1984: 36: 1309-1317.

4. Todd JA, Bell JL, McDevitt HO. HLA-DQ $\beta$ gene contributes to susceptibility and resistance to insulin-dependent diabetes mellitus. Nature 1987: 329: 599-604.

5. Morel PA, Dorman JS, Todd JA, McDevitt HO, TRUCCO M. Aspartic acid at position 57 of the HLA-DQ beta chain protects against type 1 diabetes: a family study. Proc Natl Acad Sci U S A 1988: 85: 8111-8115.

6. Aly TA, Ide A, JAhromi MM et al. Extreme genetic risks for type 1A diabetes. Proc Natl Acad Sci U S A 2006: 103: 14074-14079.

7. Pietropaolo M, Barinas-Mitchell E, Kuller LH. Perspectives in diabetes heterogeneity of diabetes mellitus. Unraveling a dispute: is systemic inflammation related to islet autoimmunity? Diabetes 2007: 56: 11891197.

8. Delovitch TL, Singh B. The nonobese diabetic mouse as a model of autoimmune diabetes: immune dysregulation gets the NOD. Immunity 1997: 7: 727-738.

9. Katz JD, Benoist C, Mathis D. T helper cell subsets in insulin-dependent diabetes. Science 1995: 268: 11851188.

10. Rabinovitch A, Suarez-Pinzon WL, Sorensen O. Interleukin 12 mRNA expression in islets correlates with beta-cell destruction in NOD mice. J Autoimmun 1996: 9: 645-651.

11. Von Herrath MG, Oldstone MB. Interferon-gamma is essential for destruction of beta-cells and development of insulin-dependent diabetes mellitus. J Exp Med 1997: 185: 531-539.

12. Wong FS, Janeway CA. The role of CD4 and CD8 $\mathrm{T}$ cells in type 1 diabetes in the NOD mouse. Res Immunol 1997: 148: 327-332.
13. Yoon JW, Jun HS, Santamaria P. Cellular and molecular mechanisms for the initiation and progression of beta-cell destruction resulting from the collaboration between macrophages and T cells. Autoimmunity 1998: 127: 109-112.

14. Lee KU, Kim MK, Amano $\mathrm{K}$ et al. Preferential infiltration of macrophages during early stages of insulitis in diabetes-prone BB rats. Diabetes 1989: 37: 1053-1058.

15. Voorbij HA, Jeucken PH, Kabel PJ, De HaAn M, Drexhage HA. Dendritic cells and scavenger macrophages in pancreatic islets of pre-diabetic BB rats. Diabetes 1989: 38: 1623-1629.

16. Jansen A, Homo-Delarche F, Hooijkaas H, Leenen PJ, Dardenne M, Drexhage HA. Immunohistochemical characterization of monocyte-macrophage and dendritic cells in the initiation of insulitis and beta cell destruction in NOD mice. Diabetes 1994: 43: 667-675.

17. Lee KU, Amano K, Yoon JW. Evidence for initial involvement of macrophages in development of insulitis in NOD mice. Diabetes 1988: 37: 989-991.

18. Beyan H, Buckley LR, Yousaf N, Londei M, Leslie RDG. A role for innate immunity in type 1 diabetes? Diabetes Metab Res Rev 2003: 19: 89-100.

19. Rabinovitch A, Suarez-Pinzon W. Cytokines and their roles in pancreatic islet $B$ cell destruction and insulin dependent diabetes mellitus. Biochem Pharmacol 1998: 55: 1139-1149.

20. Jun HS, Yoon CS, Zbytnuik L, van Rooijen N, Yoon $\mathrm{JW}$. The role of macrophages in T-cell mediated autoimmune diabetes in nonobese diabetic mice. J Exp Med 1999: 189: 347-358.

21. Oschilewski U, Kiesel U, Kolb H. Administration of silica prevents diabetes in BB rats. Diabetes 1985: 34: 197-199.

22. Lee KU, Pak CY, Amano K, Yoon JW. Prevention of lymphocytic thyroiditis and insulitis in diabetes prone $\mathrm{BB}$ rats by the depletion of macrophages. Diabetologia 1988: 31: 400-402.

23. Atrinson MA, Eisenbarth GS. Type I diabetes: new perspectives on disease pathogenesis and treatment. Lancet 2001: 358: 221-229.

24. Medzhitov R, Janeway CA Jr. Innate immunity: the virtues of a nonclonal system of recognition. Cell 1997: 91: 295-298.

25. Bottazzo GF, Dean BM, McNally JM, Mackay EH, Swift PG, Gamble DR. In situ characterization of autoimmune phenomena and expression of HLA molecules in the pancreas in diabetic insulitis. N Engl J Med 1985: 313: 353-360.

26. Conrad B, Weidman E, Trucco $G$ et al. Evidence for superantigen involvement in insulin-dependent diabetes mellitus etiology. Nature 1994: 371: 351-355.

27. Wong FS, Karttunen J, Dumont C et al. Identification of an MHC class I-restricted autoantigen in type 1 diabetes by screening an organ-specific cDNA library. Nat Med 1999: 5: 1026-1031.

28. Lieberman SM, Evans AM, Han B et al. Identification of the beta cell antigen targeted by a prevalent population of pathogenic $\mathrm{CD}+8 \mathrm{~T}$ cells in autoimmune diabetes. Proc Natl Acad Sci U S A 2003: 100: 8384 8388.

29. Khatrri R, Cox T, Yasayko SA, Ramsdell F. An essential role for Scurfin in CD+4CD+25 T-regulatory cells. Nat Immunol 2003: 4: 337-342.

30. Fontenot JD, Gavin MA, Rudensky AY. FoxP3 programs the development and function of $\mathrm{CD}+4$ CD + 25 regulatory T-cells. Nat Immunol 2003: 4: 330-336.

31. Hori S, Nomura T, Sakaguchi S. Control of regulatory $\mathrm{T}$ cell development by the transcription factor Foxp3. Science 2004: 299: 1057-1061. 
32. Randolph DA, Fathman CG. CD $+4 \mathrm{CD}+25$ regulatory $\mathrm{T}$ cells and their therapeutic potential. Annu Rev Med 2006: 57: 381-402.

33. St Clair EW, Turka LA, Saxon A et al. New reagents on the horizon for immune tolerance. Annu Rev Med 2007: 58: 329-346.

34. Bluestone JA, TAng Q. How do CD4+CD25+ regulatory $\mathrm{T}$ cells control autoimmunity? Curr Opin Immunol 2005: 17: 638-642.

35. TAng Q, Bluestone JA. Regulatory T-cell physiology and application to treat autoimmunity. Immunol Rev 2006: 212: 217-237.

36. Brusko TM, Wasserfall CH, Clare-salzler MJ, Schatz DA, Atkinson MA. Functional defects and the influence of age on the frequency of $C D+4 C D+25$ T-cells in type 1 diabetes. Diabetes 2005: 54: 1407-1414.

37. Lindley S, Dayan CM, Bishop A, Roep BO, Peakman M, TREe TI. Defective suppressor function in $\mathrm{CD}+4 \mathrm{CD}+25 \mathrm{t}$ cells from patients with type 1 diabetes. Diabetes 2005: 54: 92-99.

38. Putnam AL, Vendrame F, Dotta F, Gottlieb PA. $\mathrm{CD}+4 \mathrm{CD}+25$ high regulatory $\mathrm{T}$ cells in human autoimmune diabetes. J Autoimmun 2005: 24: 55-62.

39. Mason D, Powrie F. Control of immune pathology by regulatory T cells. Curr Opin Immunol 1998: 10: 649655.

40. TAng Q, Henrikson KJ, Bi M et al. In vitro-expanded antigen specific regulatory $\mathrm{T}$ cells suppress autoimmune diabetes. J Exp Med 2004: 199: 1455-1465.

41. Bendelac A. Mouse $\mathrm{NK}+1 \mathrm{~T}$ cells. Curr Opin Immunol 1995: 7: 367.

42. Bendelac A, Rivera MN, Park SH, Roark JH. Mouse CD1-specific NK1 T cells - development, specificity, and function. Annu Rev Immunol 1997: 15: 535-562.

43. Macdonald HR. NK1. $1+\mathrm{T}$ cell receptor- $\alpha \beta+$ cell new clues to their origin, specificity, and function. J Exp Med 1995: 182: 633-638.

44. Burdin N, Brossay L, Kronenberg M. Immunization with $\alpha$-galactosylceramide polarizes CD1-reactive NK T-cells toward Th2 cytokine synthesis. Eur J Immunol 1999: 29: 2014-2025.

45. Singh N, Hong S, Scherer DC et al. Cutting edge: activation of NK T-cells by CD1d and $\alpha$-galactosylceramide directs conventional $\mathrm{T}$ cells to the acquisition of a Th2 phenotype. J Immunol 1999: 163: 2373-2377.

46. Gombert JM, Herbelin A, Tancrede-Bohin E, Dy M, CARnaud C, BACH JF. Early quantitative and functional deficiency of $\mathrm{NK}+1$ like thymocytes in the NOD mouse. Eur J Immunol 1996: 26: 2989-2998.

47. Godfrey Di, Kinder SJ, Silvera P, Baxter AG. Flow cytometric study of $\mathrm{T}$ cell development in NOD mice reveals a deficiency in $\alpha \beta T C R+$ CD- 4 CD- 8 thymocytes. J Autoimmun 1997: 10: 279-285.

48. Wilson SB, Kent SC, Patton KT et al. Extreme Th1 bias of invariant $\mathrm{V} \alpha 24 \mathrm{~J} \alpha \mathrm{Q} \mathrm{T}$ cells in type 1 diabetes. Nature 1998: 391: 177-181.

49. Hammond KJL, Poulton LD, Palimsano LJ, Silveira PA, Godfrey DI, BAXTer AG. $\alpha \beta-T$ cell receptor $(\mathrm{TCR})+\mathrm{CD}-4$ CD-8 (NKT) thymocytes prevent insulin-dependent diabetes mellitus in nonobese diabetic (NOD/Lt) mice by the influence of interleukin-4 (IL-4) and/or IL-10. J Exp Med 1998: 187: 10471056.

50. Godfrey Di, Hammond KJ, Poulton LD, Smyth MJ, BAXTER AG. NKT cells: facts, functions and fallacies. Immunol Today 2000: 21: 573-583.

51. Takeda K, Kaisho T, Akira S. Toll-like receptors. Annu Rev Immunol 2003: 21: 335-376.
52. Dabbagh K, Lewis DB. Toll-like receptors and Thelper-1/T-helper-2 responses. Curr Opin Infect Dis 2003: 16: 199.

53. Pasare C, Medzhitov R. Toll-like receptors and acquired immunity. Semin Immunol 2004: 16: 23-26.

54. Akira S, Uematsu S, Takeuchi O. Pathogen recognition and innate immunity. Cell 2006: 124: 783801.

55. Johnson GB, Brunn GJ, Platt JL. Activation of mammalian Toll-like receptors by endogenous agonists. Crit Rev Immunol 2003: 23: 15.

56. Ohashi K, Burkart V, Flohe S, Kolb H. Cutting edge: heat shock protein 60 is a putative endogenous ligand of the Toll-like receptor-4 complex. J Immunol 2000: 164: 558.

57. Buttari B, Profumo E, Mattei V et al. Oxidized beta2glycoprotein I induces human dendritic cell maturation and promotes a $\mathrm{T}$ helper type 1 response. Blood 2005: 106: 3880.

58. Termeer C, Benedix F, Sleeman J et al. Oligosaccharides of Hyaluronan activate dendritic cells via Toll-like receptor 4. J Exp Med 2002: 195: 99.

59. Medzhitov R. Toll-like receptors and innate immunity. Nat Rev Immunol 2001: 1: 135-145.

60. Akira S, Takeda K. Toll-like receptor signaling. Nat Rev Immunol 2004: 4: 499-511.

61. Kawai T, AkiRa S. TLR signaling. Nature 2006: 13: 816-825.

62. Wei Du, Wong SF, Chervonsky A et al. Autoimmune diabetes development in TLR and MYD88 deficient NOD mice. Diabetes 2006: 55 (Suppl. 1): A89.

63. McSorley SJ, Ehst BD, Yu Y, Gewirtz AT. Bacterial flagellin is an effective adjuvant for CD4+ $\mathrm{T}$ cells in vivo. J Immunol 2002: 169: 3914-3919.

64. Martin DA, Elkon KB. Autoantibodies make a U-turn: the toll hypothesis for autoantibody specificity. J Exp Med 2005: 202: 1465-1469.

65. Fritz JH, Le Bourhis L, Sellge G et al. Nod-like proteins in immunity, inflammation and disease. Nat Immunol 2006: 12: 1250-1257.

66. Klesney-Tait J, Turnbull IR, Colonna M. The TREM receptor family and signal integration. Nat Immunol 2006: 12: 1266-1273.

67. Robinson MJ, Sancho D, Slack EC, LeibundtGutLandmanns S, Reis e Sousa C. Myeloid C-type lectins in innate immunity. Nat Immunol 2006: 12: 1258-1265.

68. Meagher C, Sharif S, Hussain S, Cameron MJ, Arreaza GA, Delovitch TL. Cytokines and chemokines in the pathogenesis of murine type 1 diabetes. Adv Exp Med Biol 2003: 520: 133-158.

69. Varela-Calvino R, Peakman M. Enteroviruses and type 1 diabetes. Diabetes Metab Res Rev 2003: 19: $431-441$.

70. Green J, Casabonne D, Newton R. Coxsackie B virus serology and type I diabetes mellitus: a systemic review of published case-control studies. Diabet Med 2004: 21: 507-514.

71. Barbu AR, Akusjarvi G, Welsh N. Adenoviralmediated transduction of human pancreatic islets: importance of adenoviral genome for cell viability and association with a deficient antiviral response. Endocrinology 2005: 146: 2406-2414.

72. Chen LK, Chou YC, Tsai ST, Hwang SJ, Lee SD. Hepatitis $C$ virus infection-related type 1 diabetes mellitus. Diabet Med 2005: 22: 340-343.

73. Mohammad MK, Morran M, Slotterbeck B et al. Dysregulated Toll-like receptor expression and signaling in bone marrow derived macrophages at the onset of 
diabetes in the non-obese diabetic mouse. Int Immunol 2007: 18: 1101-1113.

74. Moriyama H, Wen L, Abiru $\mathrm{N}$ et al. Induction and acceleration of insulitis/diabetes in mice with a viral mimic (polyinosinic-polycytidylic acid) and an insulin self-peptide. Proc Natl Acad Sci U S A 2002: 99: 5539.

75. HondA K, TANIGUCHI T. IRFs: master regulators of signaling by Toll-like receptors and cytosolic pattern recognition receptors. Nat Rev 2006: 6: 644-658.

76. Hussain MJ, Peakman M, Gallati $H$ et al. Elevated serum levels of macrophage-derived cytokines precede and accompany the onset of IDDM. Diabetologia 1996: 39: 60.

77. Shanmugam N, Reddy M, Guha M, Natarajan R. High glucose-induced expression of proinflammatory cytokine and chemokine genes in monocytic cells. Diabetes 2003: 52: 1256.
78. Kabelitz D. Expression and function of Toll-like receptors in T lymphocytes. Curr Opin Immunol 2007: 19: 39-45.

79. Hornung V, Rothenfusser S, British $\mathrm{S}$ et al. Quantitative expression of Toll-like receptor 1-10 mRNA in cellular subsets of human peripheral blood mononuclear cells and sensitivity to $\mathrm{CpG}$ oligodeoxynucleotides. J Immunol 2002: 168: 4531-4537.

80. Zarember KA, Godowski PJ. Tissue expression of Tolllike receptors and differential regulation of Toll-like receptor mRNA in leukocytes in response to microbes, their products, and cytokines. J Immunol 2002: 168: 554-561.

81. Caron G, Duluc D, Fremaux I et al. Direct stimulation of human T-cells via TLR5 and TLR7/8 and R-848 upregulate proliferation and IFN-g production by memory CD+4 T-cells. J Immunol 2005: 175: 1551-1557. 